Original article

\title{
Age-related relationships between muscle fat content and metabolic traits in growing rabbits
}

\author{
Florence GONDRET $^{\mathrm{a} *}$, Jean-François HOCQUETTE ${ }^{\mathrm{b}}$, Patrick HERPIN ${ }^{\mathrm{a}}$ \\ a INRA, Unité Mixte de Recherches sur le Veau et le Porc, 35590 Saint-Gilles, France \\ b INRA, Unité de Recherches sur les Herbivores, 63122 Saint-Genès-Champanelle, France
}

(Received 8 April 2003; accepted 24 October 2003)

\begin{abstract}
This study was aimed at ascribing muscle fat accretion in growing rabbits to changes in several extra-muscular and intra-muscular metabolic pathways. At $10 \mathrm{wk}$ or $20 \mathrm{wk}$ of age $(n=8$ per group), tissue lipid content and metabolic indicators of nutrient anabolic or catabolic pathways were simultaneously assessed in the liver, perirenal fat, the heart and the Longissimus lumborum (LL) muscle, together with plasma concentrations in energy-yielding metabolites. Lipid content significantly increased with age $(P \leq 0.01)$ in the glycolytic LL muscle $(+67 \%)$ and the oxidative heart $(+30 \%)$. In the former muscle, it was statistically correlated $\left(r^{2}=0.68 ; P<0.01\right)$ to the changes in the orientation of muscle metabolism towards an enhanced lipogenic capacity and a depressed capacity for fatty acid transport and nutrient oxidation, and to indications of lower availability in plasma glucose and triglycerides. In the heart, age-related fat accretion was positively associated $\left(r^{2}=\right.$ $0.48, P<0.01$ ) to intrinsic metabolic changes towards an enhanced lipogenic capacity, together with a lower availability in plasma glucose. Variables representative of cardiac catabolic capacity tended to be negatively correlated to fat content in the heart $\left(r^{2}=0.15, P=0.07\right)$. In growing rabbits, muscle fat content variation was proven to result from a reciprocal balance between catabolic and anabolic fatty acid fluxes, rather than to be assigned to one specific energy metabolic pathway.
\end{abstract}

rabbits / muscle / lipogenesis / fatty acid binding proteins / oxidation / lipoprotein lipase

\section{INTRODUCTION}

Lipid stores in skeletal muscles play a crucial role in the muscle physiology of healthy individuals [1], and in metabolic disorders such as obesity [2] and insulin resistance [3], which are major public health concerns nowadays. In the heart, excessive deposition of intra-muscular lipids is accompanied by an increased cell apoptosis and a loss of cardiac function [4]. In addition, in farm animals, muscle lipid content has been recognized as a key determinant of dietetic (for a review, see [5]) and sensory (for a review, see [6]) meat quality traits. Rabbits have several advantages over laboratory rodents and other meatproducing animals. First, they are considered as a superior model than mice and rats for the study of lipid metabolism in humans [7]. Unlike rodents, they are also of direct agronomic value in Europe, especially regarding meat production. Interestingly, an age-related increase in triglycerides (TG) and the total lipid contents have been clearly demonstrated in skeletal muscles of growing rabbits $[8,9]$.

* Corresponding author: gondret@st-gilles.rennes.inra.fr 
Intra-muscular fat represents the lipids stored to a minor extent within the myofibers, and to a major extent within the adipocytes interspersed in the perimysium [8]. Nutrients are continuously exchanged between muscle fibers and adipocytes through micro-vessels, and also between muscles and other tissues or organs through the general blood circulation. However, to our knowledge, conclusive evidence is still lacking for the relative contribution of (i) extra-muscular and intra-muscular substrate availability, (ii) tissue hydrolysis of circulating lipoprotein-associated TG via lipoprotein lipase (LPL), (iii) cellular trafficking of fatty acids (FA), that is facilitated by molecules such as FA transport proteins and CD36 receptor (for a review, see [10]), and FA binding proteins $(\mathrm{FABP}$, for a review, see [11]), (iv) activities of key enzymes that direct FA towards storage or oxidation [6]. In the rabbit, pure oxidative muscles display a higher fat content than predominantly glycolytic ones $[8,12]$. However, an other study investigating various muscles of oxidative, glycolytic or mixed metabolic types [12], failed to show any strict association between the relative proportion of oxidative fibers in the muscles and their respective fat content. Muscle lipid accretion has been reported to be parallel to the growth pattern of muscle lipogenic enzyme activities [13], but a causal relationship has not yet been demonstrated. Our aim was to depict how age-related changes in the relative importance of several energy anabolic and catabolic pathways in the body and in muscles could account for growth-induced variations in muscle lipid content in rabbits.

\section{MATERIALS AND METHODS}

\subsection{Animals and sample collection}

All animal protocols were conducted in compliance with French guidelines for human care and use of animals in research. New-Zealand White male rabbits were obtained from the experimental breeding station at Le Magneraud (INRA, Surgères, France). From weaning to death, the rabbits were given free access to water and to a standard pelleted diet, containing $16.4 \%$ cellulose, $16.5 \%$ crude protein, $2.8 \%$ fat, and $3790 \mathrm{kcal} \cdot \mathrm{kg}^{-1}$ gross energy. The rabbits ( $n=8$ in each age group) were slaughtered at the fed state by electrical stunning and exsanguination at $10 \mathrm{wk}(2398 \pm 111 \mathrm{~g}$ $\mathrm{BW}$, commercial slaughter), or $20 \mathrm{wk}$ of age $(4261 \pm 82 \mathrm{~g} \mathrm{BW}$, sexual maturity). Blood samples were immediately collected from the jugular vein. Plasma was prepared at $4{ }^{\circ} \mathrm{C}$ by low-speed centrifugation at $1500 \times$ $g$ for $15 \mathrm{~min}$ and then stored at $-20^{\circ} \mathrm{C}$. At the time of death, the liver and the white perirenal adipose tissue (WAT) were dissected, since they are the main sites for FA oxidation and lipogenesis, respectively [14]. Two muscles were also excised from the carcass. The Longissimus lumborum (LL) muscle (1st-5th lumbar vertebra level) was chosen because of its importance for the rabbit meat industry. It represents mainly glycolytic fast-twitch fibers, at a ratio of $92 \%$ fast-twitch glycolytic type IIB+IIX, $6 \%$ oxido-glycolytic type IIA, and $2 \%$ oxidative type I on average, for 10 -wk rabbits [8]. The heart is composed of type I (ventricles) and type $\alpha$-cardiac (atrial tissue) myosin heavy chains [15]. It offers the advantage of being one of the rare pure oxidative slow-twitch muscles in rabbits of direct interest for human physiology (cardio-vascular diseases), being sometimes eaten (edible offal), and also having a sufficient size $(\approx 7 \mathrm{~g})$ to allow many measurements. The absence of any visible signs of contamination from inter-muscular fat was carefully checked in both muscles when cutting. The samples were immediately frozen in liquid nitrogen, and stored at $-80^{\circ} \mathrm{C}$.

\subsection{Plasma energy-metabolite content and tissue lipid content}

Plasma concentrations in energy-yielding metabolites were determined on $10 \mu \mathrm{L}$ of plasma with enzymatic methods adapted 
to a Cobas Mira multi-analyzer apparatus (ABX, Montpellier, France), using commercially available kits for TG (PAP 150, Biomérieux, Marcy-l'Étoile), glucose (PAP 1200, BioMérieux, Marcy-l'Étoile), and free fatty acids (FFA, NEFA C-test, Wako Chemicals, Dardilly, France). All assays were performed in duplicate.

Total lipid content was determined in duplicate in all tissues after extraction with chloroform/methanol [16] and expressed as $\mathrm{g}$ per $100 \mathrm{~g}$ of fresh tissue.

\subsection{Blood triglyceride hydrolysis and intracellular transport of fatty acids}

Extra-hepatic LPL activity was assayed in tissue extracts from WAT, the heart and LL muscle, according to the method described for bovine tissues [17]. LPL activity was expressed as nmol FFA released/ min per $g$ wet tissue weight. The expression of LPL has been detected in the neonatal liver [18], but adult liver expresses hepatic lipase closely related, but not identical to LPL.

Tissue content in FABP was determined by ELISA analysis [19] on cytosolic protein preparations from WAT, the heart and LL muscle, using a polyclonal antibody raised against rat adipocyte isoform (A-FABP), or against rat heart and skeletal muscle isoform (H-FABP), respectively. The results are expressed in arbitrary densitometric units per mg of cytosolic proteins, since pure rabbit FABP are not available to convert the data in $\mu \mathrm{g}$ per $g$ wet tissue weight.

\subsection{Lipogenic enzymes}

Frozen samples were homogenized in ice-cold buffer containing $0.25 \mathrm{M}$ sucrose, $1 \mathrm{mM}$ dithiothreitol, $1 \mathrm{mM}$ EDTA, and protease inhibitors (Roche Applied Science, Mannheim, Germany). Homogenates were centrifuged (i) at $100000 \times g$ for $1 \mathrm{~h}$ at $4{ }^{\circ} \mathrm{C}$ [20], for the determination of fatty acid synthase (FAS) activity, or (ii) at $30000 \times g$ for
40 min at $4{ }^{\circ} \mathrm{C}[13]$ for the determination of acetyl-CoA carboxylase (ACC), and NADPH-producing enzymes (malic enzyme: $\mathrm{ME}$, and glucose-6-phosphate dehydrogenase: G6PDH). The resulting supernatants were used for the enzyme assays. The activities of FAS, ME and G6PDH were assessed spectrophotometrically at $340 \mathrm{~nm}$, according to the methods described by Bazin and Ferré [20]. The linearity of the reaction was ensured for at least $8 \mathrm{~min}$ after the substrates had been added. FAS activity in some muscle samples was found just below the detectable level of the assay, and thus FAS activity is not included in the data sets for LL muscle and the heart. ACC activity was determined by the $\mathrm{H}^{14} \mathrm{CO}_{3}$ - fixation method using $\left[1-{ }^{14} \mathrm{C}\right]$ acetate [21]. In the assay, ACC is maximally activated by citrate (provided in excess), using ATP and glutathion as cofactors, so the activity does not reflect the actual rate in vivo but represents the maximum potential of the enzyme under optimal conditions. One unit of activity was defined as the amount of enzyme that reduced $1 \mathrm{nmol} \cdot \mathrm{min}^{-1}$ of nucleotide (FAS, ME, and G6PDH) or incorporated $1 \mathrm{nmol} \cdot \mathrm{min}^{-1}$ of bicarbonate (ACC). Enzyme activities were expressed as units per $\mathrm{g}$ of fresh tissue.

\subsection{Oxidative and glycolytic enzymes}

The activity levels of some energy catabolic pathways were determined in all samples, except WAT that is not a predominant site for energy expenditure in the body. Tissue samples were homogenized and sonicated in ice-chilled sucrose-Tris-EDTA buffer. After centrifugation at $1700 \times g$ for $15 \mathrm{~min}$ at $4{ }^{\circ} \mathrm{C}$, the supernatant fraction (soluble enzymes and mitochondrial material) was collected and used for further analyses. The maximal activity levels of the enzymes, reflecting the potential for FA $\beta$-oxidation ( $\beta$-hydroxyacyl-CoA dehydrogenase, HAD, [22]), mitochondrial density (citrate synthase, CS, [23]), oxidative phosphorylation (cytochrome- $c$ oxidase, 
COX, [24]), or glycolytic metabolic pathway (phosphofructokinase, PFK, [25]) were determined spectrophotometrically. One unit of the enzyme was defined as the amount which catalyses per min the disappearance of $1 \mu \mathrm{mol}$ of NADH for HAD and PFK, the liberation of $1 \mu \mathrm{mol}$ of coenzyme A for CS, and the oxidation of $1 \mu \mathrm{mol}$ of cytochrome- $c$ for COX. The results were expressed as units per $\mathrm{g}$ tissue fresh weight.

\subsection{Statistical analyses}

Within each site of sampling, data were analyzed using the GLM procedure of SAS (Statistical Analysis System, Cary, NC, NY, USA), with age as the main effect. Data for plasma concentrations in metabolites and tissue characteristics are presented as means in each age group, together with the standard error of the treatment means. Significance was denoted at $P \leq 0.05$ level. The probability value less than 0.10 was discussed as a trend.

Principal component analysis (PCA) was performed using the PRINCOMP procedure of SAS, to study the relationships between plasma concentrations in metabolites and FA pathways in the liver and in WAT. The following variables measured on $10 \mathrm{wk}$ and $20 \mathrm{wk}$ were used: plasma concentrations of glucose, TG, FFA, lipid content in WAT, anabolic FA pathway in WAT (LPL, A-FABP, FAS, ACC, ME, G6PDH), hepatic lipid content, and anabolic (FAS, ME, G6PDH) and catabolic (HAD, CS, $\mathrm{COX}$ ) activities in the liver. Three principal components (PC), defined as linear combinations of the original variables, were calculated from the eigenvectors of the correlation matrix of the 18 variables and 16 rabbits. The results were presented graphically on an xy plane, the farther away a variable is from the two axes origin, the better it is represented on the considered plane. To ensure that a variable contributes significantly to the determination of the PC, a Pearson correlation analysis was performed between the input variable and each PC, using the CORR procedure of SAS. The plot can also be viewed as a graphical representation of correlation coefficients: for variables away from the origin, an angle between 2 points of less than $90^{\circ}$ indicates a positive relationship, and an angle of more than $90^{\circ}$ indicates a negative correlation. These first three PC were noted $\mathrm{PC}_{\mathrm{FFA}}$, $\mathrm{PC}_{\mathrm{glucose}}$ and $\mathrm{PC}_{\mathrm{TG}}$, respectively.

Within LL muscle and within the heart, PCA were then performed to study the relationships between extra-muscular trends and muscle intrinsic variables. As far as the extra-muscular variables are concerned, individual scores for $\mathrm{PC}_{\mathrm{FFA}}, \mathrm{PC}_{\text {glucose }}$ and $\mathrm{PC}_{\mathrm{TG}}$ were used, since they were judged to adequately describe body FA metabolic trends. As for intrinsic muscle metabolic characteristics, we used the following variables measured at $10 \mathrm{wk}$ and $20 \mathrm{wk}$, representative of either anabolic FA pathway (LPL, H-FABP, ACC, ME, G6PDH) or catabolic nutrient activities (PFK, HAD, CS, $\mathrm{COX}$ ). In each muscle site, three PC were thereby calculated from the eigenvectors of the correlation matrix of the 12 variables and 16 rabbits. The results are presented graphically and significance tests were performed, as described above.

In each muscle, the PC thus obtained were used as new independent variables in a regression analysis [26] to predict muscle fat content, using stepwise multiple linear regression of the SAS package.

\section{RESULTS}

\subsection{Influence of age on plasma concentrations in metabolites}

Plasma concentrations in energy-yielding substrates are given in Table I. Plasma glucose in rabbits at the steady state was almost constant whatever the age group. On the contrary, the concentration of FFA in the blood, that varied widely between individuals [27], displayed a 3-fold increase with age $(P \leq 0.05)$. By contrast, plasma concentration in TG tended to be 1.5 fold lower at $20 \mathrm{wk}$ than at $10 \mathrm{wk}$ of age. 
Table I. Influence of age on plasma concentrations in energy-yielding metabolites. Means \pm standard errors of the means are reported.

\begin{tabular}{lcccc}
\hline Plasma concentrations & $10 \mathrm{wk}$ & $20 \mathrm{wk}$ & SEM $^{1}$ & Statistics $^{2}$ \\
\hline Glucose $\left(\mathrm{mg} \cdot \mathrm{L}^{-1}\right)$ & 1610 & 1480 & 189 & $\mathrm{NS}$ \\
Free fatty acids $\left(\mu \mathrm{mol} \cdot \mathrm{L}^{-1}\right)$ & 371 & 1100 & 651 & $*$ \\
Triglycerides $\left(\mu \mathrm{mol} \cdot \mathrm{L}^{-1}\right)$ & 843 & 562 & 349 & $\dagger$ \\
\hline
\end{tabular}

${ }^{1}$ SEM: standard error of treatment means $(n=16)$.

2 Age effect: $* P \leq 0.5, \dagger P \leq 0.10$, NS: not significant.

Table II. Influence of age on lipid content and metabolic characteristics of the liver. Means \pm standard errors of the means are reported.

\begin{tabular}{lcccc}
\hline Liver traits & $10 \mathrm{wk}$ & $20 \mathrm{wk}$ & $\mathrm{SEM}^{1}$ & Statistics $^{2}$ \\
\hline Lipid content (g per 100 g) & 4.1 & 5.2 & 0.5 & $* *$ \\
Enzymes of de novo lipogenesis & $\left(\mathrm{nmol} \cdot \mathrm{min}^{-1}\right.$ per $\mathrm{g}$ tissue) & & & \\
$\quad$ Fatty acid synthase & 379 & 774 & 277 & $*$ \\
Acetyl-CoA carboxylase & 60 & 88 & 29 & $\dagger$ \\
Malic enzyme & 397 & 473 & 276 & $\mathrm{NS}$ \\
G6PDH & 3624 & 3720 & 930 & $\mathrm{NS}$ \\
Enzyme of oxidative energy pathways $\left(\mu \mathrm{mol} \cdot \mathrm{min}^{-1}\right.$ per g tissue) & 6.9 & 0.8 & $\mathrm{NS}$ \\
Citrate synthase & 7.1 & 24 & 9.9 & $* *$ \\
Cytochrome- $c$ oxidase $^{3}$ & 42 & 2.9 & 0.9 & $\mathrm{NS}$ \\
HAD $^{3}$ & 3.3 & & & \\
\hline
\end{tabular}

${ }^{1}$ SEM: standard error of treatment means $(n=16)$.

2 Age effect: $* * P \leq 0.01 ; * P \leq 0.5, \dagger P \leq 0.10$, NS: not significant.

${ }^{3} \mathrm{G} 6 \mathrm{PDH}=$ glucose-6-phosphate dehydrogenase, $\mathrm{HAD}=\beta$-hydroxyacyl-CoA dehydrogenase .

\subsection{Influence of age on tissue lipid contents and metabolic characteristics}

Lipid content increased with age in the liver (Tab. II), and this increase was paralleled by an increase in the activities of key lipogenic enzymes (FAS, $P \leq 0.05$; and ACC, $P=0.08)$. COX activity was decreased by $43 \%(P \leq 0.01)$ between 10 and $20 \mathrm{wk}$, whereas other oxidative enzyme activities remained stable during this period.

Lipid content in WAT remained almost stable between 10 and 20 wk (Tab. III), despite a decrease in the anabolic capacity for FA storage (LPL, FAS, $P<0.05$; ACC,
$P=0.10)$. As expected [13], ME activity was very low compared to G6PDH activity in the WAT rabbit.

Muscle lipid content markedly increased with age $(+67 \%$ in the LL, Tab. IV; $+30 \%$ in the heart, Tab. $\mathrm{V}$, respectively). In the LL, this increase was paralleled by an enhanced capacity for FA synthesis, and a decreased potential for nutrient oxidative catabolism (CS, HAD, $P \leq 0.10)$. The activity of COX did not follow the same agerelated pattern that other oxidative catabolic enzymes followed ( $+76 \%$ between 10 and $20 \mathrm{wk}, P \leq 0.001)$. Finally, LPL, the enzyme responsible for circulating $\mathrm{TG}$ hydrolysis, markedly decreased with age 
Table III. Influence of age on lipid content and metabolic characteristics in perirenal white adipose tissue (WAT). Means \pm standard errors of the means are reported.

\begin{tabular}{|c|c|c|c|c|}
\hline WAT traits & $10 \mathrm{wk}$ & $20 \mathrm{wk}$ & SEM $^{1}$ & Statistics $^{2}$ \\
\hline Lipid content (g per $100 \mathrm{~g}$ ) & 68 & 71 & 6 & NS \\
\hline \multicolumn{5}{|c|}{ Enzymes of de novo lipogenesis (nmol· $\mathrm{min}^{-1}$ per g tissue) } \\
\hline Fatty acid synthase & 78 & 23 & 43 & $* *$ \\
\hline Acetyl-CoA carboxylase & 18 & 10 & 8 & $\dagger$ \\
\hline Malic enzyme & 72 & 56 & 64 & NS \\
\hline $\mathrm{G} \mathrm{PDH}^{3}$ & 1189 & 989 & 345 & NS \\
\hline \multicolumn{5}{|c|}{ Enzyme of circulating triglyceride hydrolysis (nmole $\cdot \min ^{-1}$ per $g$ tissue) } \\
\hline Lipoprotein lipase & 1299 & 578 & 440 & $*$ \\
\hline \multicolumn{5}{|c|}{ Transport of intracellular fatty acids (arbitrary units per mg cytosolic proteins) } \\
\hline A-FABP 3 & 266 & 225 & 56 & NS \\
\hline
\end{tabular}

${ }^{1}$ SEM: standard error of treatment means $(n=16)$.

2 Age effect: $* * P \leq 0.01 ; * P \leq 0.5, \dagger P \leq 0.10$, NS: not significant.

$3 \mathrm{~A}-\mathrm{FABP}=$ fatty acid binding protein, adipocyte isoform, G6PDH = glucose-6-phosphate dehydrogenase.

Table IV. Influence of age on lipid content and metabolic characteristics of the Longissimus lumborum (LL) muscle. Means \pm standard errors of the means are reported.

\begin{tabular}{|c|c|c|c|c|}
\hline LL traits & $10 \mathrm{wk}$ & $20 \mathrm{wk}$ & SEM $^{1}$ & Statistics $^{2}$ \\
\hline Total lipid content (g per $100 \mathrm{~g}$ ) & 1.2 & 2.0 & 0.4 & $* *$ \\
\hline \multicolumn{5}{|c|}{ Enzymes of de novo lipogenesis (nmol-min $\mathrm{min}^{-1}$ per $\mathrm{g}$ tissue) } \\
\hline Acetyl-CoA carboxylase & 0.3 & 1.1 & 0.7 & $*$ \\
\hline Malic enzyme & 188 & 268 & 61 & $*$ \\
\hline $\mathrm{G} \mathrm{PDH}{ }^{3}$ & 16 & 44 & 16 & $* *$ \\
\hline \multicolumn{5}{|c|}{ Enzymes of catabolic nutrient pathways ( $\mu \mathrm{mol} \cdot \mathrm{min}^{-1}$ per $\mathrm{g}$ tissue $)$} \\
\hline Citrate synthase & 6.5 & 5.3 & 0.8 & $*$ \\
\hline $\mathrm{HAD}^{3}$ & 1.2 & 0.8 & 0.4 & $\dagger$ \\
\hline Cytochrome- $c$ oxidase & 5.8 & 10.2 & 1.5 & $* * *$ \\
\hline Phosphofructokinase & 12 & 13 & 5.4 & NS \\
\hline \multicolumn{5}{|c|}{ Enzyme of circulating triglyceride hydrolysis $\left(\mathrm{nmol} \cdot \mathrm{min}^{-1}\right.$ per $\mathrm{g}$ tissue) } \\
\hline Lipoprotein lipase & 461 & 152 & 172 & ** \\
\hline \multicolumn{5}{|c|}{ Transport of intracellular fatty acids (arbitrary units per mg cytosolic proteins) } \\
\hline $\mathrm{H}-\mathrm{FABP}^{3}$ content & 13.2 & 9.6 & 7.1 & NS \\
\hline
\end{tabular}

${ }^{1}$ SEM: standard error of treatment means $(n=16)$.

2 Age effect: $* * * P \leq 0.001 ; * * P \leq 0.01 ; * P \leq 0.5, \uparrow P \leq 0.10$, NS: not significant.

${ }^{3}$ G6PDH $=$ glucose-6-phosphate dehydrogenase, HAD = $\beta$-hydroxyacyl-CoA dehydrogenase, H-FABP

$=$ fatty acid binding protein, heart and skeletal muscle isoform. 
Table V. Influence of age on lipid content and metabolic characteristics of the heart. Means \pm standard errors of the means are reported.

\begin{tabular}{|c|c|c|c|c|}
\hline Cardiac traits & $10 \mathrm{wk}$ & $20 \mathrm{wk}$ & SEM $^{1}$ & Statistics $^{2}$ \\
\hline Total lipid content ( $\mathrm{g}$ per $100 \mathrm{~g}$ ) & 3.3 & 4.3 & 0.5 & $* *$ \\
\hline \multicolumn{5}{|c|}{ Enzymes of de novo lipogenesis (nmol. $\mathrm{min}^{-1}$ per g tissue) } \\
\hline Acetyl-CoA carboxylase & 1.6 & 11.0 & 2.3 & $* * *$ \\
\hline Malic enzyme & 152 & 241 & 76 & $*$ \\
\hline G6PDH ${ }^{3}$ & 255 & 236 & 108 & NS \\
\hline \multicolumn{5}{|c|}{ Enzymes of catabolic nutrient pathways ( $\mu \mathrm{mol} \cdot \mathrm{min}^{-1}$ per $\mathrm{g}$ tissue) } \\
\hline Citrate synthase & 27 & 27 & 5.9 & NS \\
\hline Cytochrome- $c$ oxidase & 45 & 61 & 16 & $\dagger$ \\
\hline $\mathrm{HAD}^{3}$ & 8.1 & 6.7 & 4.2 & NS \\
\hline Phosphofructokinase & 4.0 & 2.2 & 2.8 & NS \\
\hline \multicolumn{5}{|c|}{ Enzyme of circulating triglyceride hydrolysis $\left(\mathrm{nmol} \cdot \mathrm{min}^{-1}\right.$ per $\mathrm{g}$ tissue) } \\
\hline Lipoprotein lipase & 2426 & 2912 & 912 & NS \\
\hline \multicolumn{5}{|c|}{ Transport of intracellular fatty acids (arbitrary units per mg cytosolic proteins) } \\
\hline H-FABP ${ }^{3}$ content & 487 & 378 & 118 & $\dagger$ \\
\hline
\end{tabular}

${ }^{1}$ SEM: standard error of treatment means $(n=16)$.

2 Age effect: $* * * P \leq 0.001 ; * * P \leq 0.01 ; * P \leq 0.5, \dagger P \leq 0.10$, NS: not significant.

${ }^{3} \mathrm{G} 6 \mathrm{PDH}=$ glucose- 6 -phosphate dehydrogenase, HAD $=\beta$-hydroxyacyl-CoA dehydrogenase;

$\mathrm{H}-\mathrm{FABP}=$ fatty acid binding protein, heart and skeletal muscle isoform.

$(-67 \%)$ in the LL muscle. In the heart, the $20 \mathrm{wk}$ rabbits displayed higher activities of ACC and ME than 10 wk animals $(P \leq$ 0.05). Cardiac COX activity tended to be increased between $10 \mathrm{wk}$ and $20 \mathrm{wk}$ of age $(+35 \%)$, whereas the activities of other oxidative enzymes remained stable during the same growth period. Finally, the cardiac capacity for intracellular FA transport by H-FABP tended to decrease with age $(-22 \%, P=0.08)$. Whatever the muscle, PFK values did not differ between the two ages.

\subsection{Relationships between plasma} concentrations in energy-yielding metabolites and fatty acid metabolism in the liver and perirenal adipose tissue

Of the PCA which was carried out, the first three principal components (PC) were retained since they explained a significant part of the variability in plasma metabolite concentrations. Altogether they explained $58 \%$ of the standardized variance $(24,20$ and $14 \%$, respectively). The first $\mathrm{PC}$ $\left(\mathrm{PC}_{\mathrm{FFA}}\right)$ showed positive relationships between traits related to FA anabolism in WAT (circulating TG hydrolysis by LPL, intracellular FA transport by A-FABP, and lipogenic potential), $\mathrm{COX}$ activity in the liver, and the antagonism between these variables and the plasma level in FFA (Fig. 1a). The second PC ( $\left.\mathrm{PC}_{\text {glucose }}\right)$ reflected a strong relationship between hepatic lipid content and liver lipogenesis, and the antagonism between these variables and plasma concentration in glucose (Fig. 1a). The third PC ( $\left.\mathrm{PC}_{\mathrm{TG}}\right)$ was mainly ascribed to the plasma concentration in $\mathrm{TG}$ (Fig. 1b), which was negatively associated with the liver lipid content $(-0.44)$ and hepatic CS activity $(-0.39)$. 

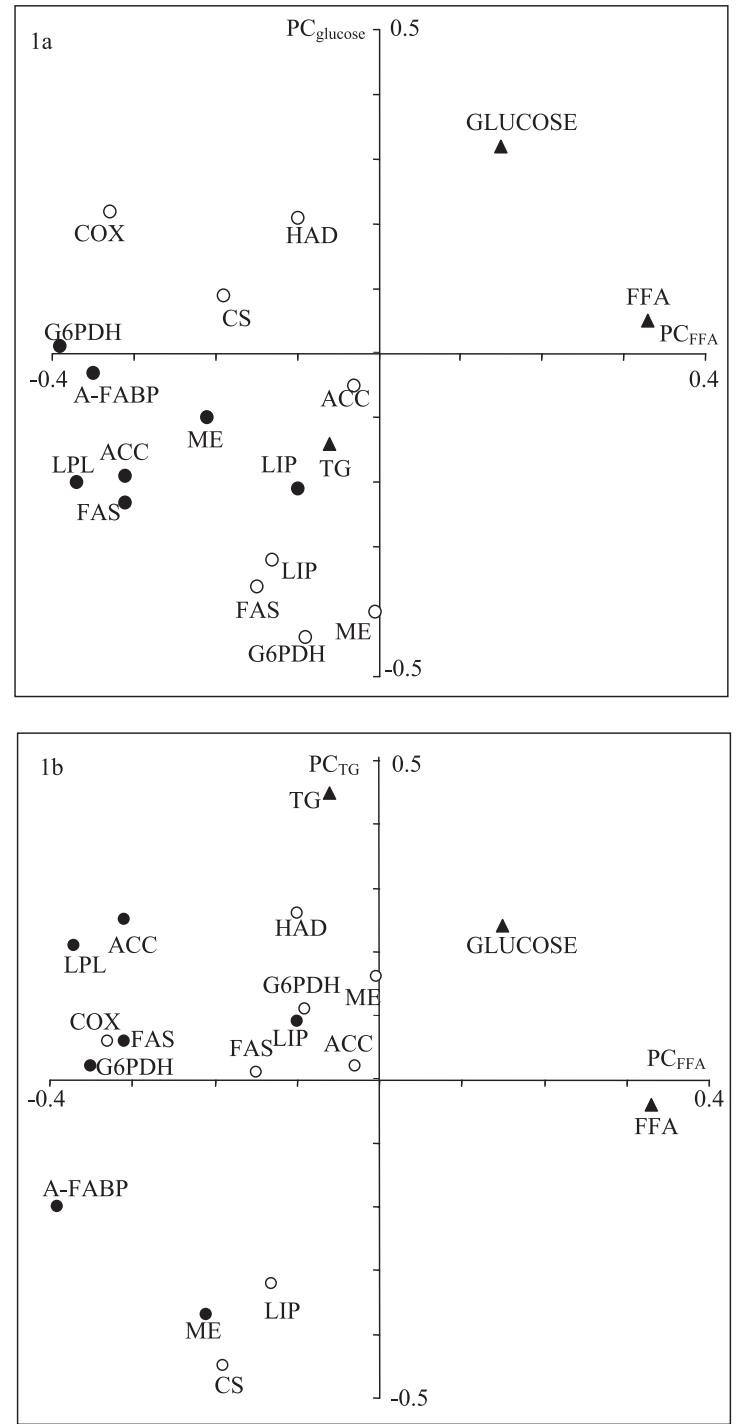

Figure 1. Principal component analyses (PCA) showing relationships between whole body fatty acid pathways and plasma concentrations in energy-yielding metabolites. The PCA were performed using the following variables measured in the liver $(\mathrm{O})$, and(or) in perirenal white adipose tissue $(\bullet)$ : (i) activities of acetyl-CoA carboxylase (ACC), fatty acid synthase (FAS), glucose-6-phosphate dehydrogenase (G6PDH), malic enzyme (ME), and lipid content (LIP); (ii) lipoprotein lipase activity (LPL) and content in adipocyte isoform of fatty acid binding protein (A-FABP); (iii) activities of citrate synthase (CS), cytochrome-c oxidase $(\mathrm{COX})$, and $\beta$-hydroxyacyl-CoA dehydrogenase (HAD); and (iv) and plasma concentrations $(\boldsymbol{\Delta})$ in glucose (GLUCOSE), free fatty acids (FFA) and triglycerides (TG). Initial variables close to each other are positively associated, whereas variables that lie opposite on the same PC are negatively correlated. The position of the points shows the contribution of each original trait to each PC: (i) the first principal component (PC) largely describes negative relationships between anabolism in WAT and plasma concentration in free fatty acids $\left(\mathrm{PC}_{\mathrm{FFA}}\right.$, Fig. 1a); (ii) the second $\mathrm{PC}$ shows negative relationships between hepatic lipogenesis and plasma concentration in glucose $\left(\mathrm{PC}_{\text {glucose }}\right.$, Fig. 1a); and (iii) the third $\mathrm{PC}$ illustrates negative relationships between hepatic lipid content and plasma triglyceride concentration $\left(\mathrm{PC}_{\mathrm{TG}}\right.$, Fig. 1b). 


\subsection{Relationships between plasma availability in energy-yielding metabolites and metabolic characteristics in the Longissimus muscle}

Relationships between metabolic traits in the LL muscle and individual scores for $\mathrm{PC}_{\mathrm{FFA}}, \mathrm{PC}_{\text {glucose }}$ and $\mathrm{PC}_{\mathrm{TG}}$ are summarized by PCA (Fig. 2). The first three PC explained $78 \%$ of the standardized variance (48, 16 and $14 \%$, respectively). The first PC (PC 1, Fig. 2a) illustrated the link between plasma concentrations in TG and glucose, and intra-muscular metabolic pathways. Indeed, it mainly showed a positive link between adjusted plasma concentration in TG $\left(\mathrm{PC}_{\mathrm{TG}}\right)$ and the muscle capacity for circulating TG hydrolysis via LPL (0.54) on the one hand, and a negative relationship between plasma glucose level and the activities of NADPH-producing enzymes, such as G6PDH (-0.84) and ME (-0.64) on the other hand. The first PC also strongly showed that the enhanced muscle capacity for lipogenesis (ME, G6PDH, ACC) was balanced by a decreased muscle potential for circulating TG hydrolysis (LPL), intracellular transport of FA (H-FABP), and oxidative catabolism (CS, HAD). Interestingly, PC 1 thus showed a positive association between H-FABP, and CS (0.56) and HAD (0.66). When projecting the individual animals along this PC axis, clear discrimination could be seen between the two age groups (Fig. 2b). The 20 wk rabbits confined to the right of the plot were thus characterized by higher activity levels for lipogenic enzymes, and a lower oxidative metabolism than $10 \mathrm{wk}$ rabbits, as well as by lower plasma concentrations in glucose and TG. The two other PC contributed three-fold less to the total variance. The second PC (PC 2, Fig. 2a) characterized the variation in plasma FFA concentration and the muscle potential for glycolysis (phosphofructokinase activity, PFK). The third PC was mainly ascribed to the adjusted plasma $\mathrm{TG}$ concentration $\left(\mathrm{PC}_{\mathrm{TG}}\right.$, data not shown).

\subsection{Relationships between blood availability in energy-yielding metabolites and metabolic characteristics in the heart}

Relationships between metabolic traits in the heart and individual scores for $\mathrm{PC}_{\mathrm{FFA}}, \mathrm{PC}_{\mathrm{glucose}}$ and $\mathrm{PC}_{\mathrm{TG}}$ were summarized by $P C A$ (Fig. 3). Each of the first three $\mathrm{PC}$ represented 30, 22 and 14\% of the initial variance, respectively. The first PC (PC 1, Fig. 3a) showed positive relationships between the activity levels of enzymes involved in glucose (PFK, CS, G6PDH) and FA (CS, HAD) catabolism, and the antagonism between these variables and adjusted plasma FFA concentration $\left(\mathrm{PC}_{\mathrm{FFA}}\right)$. The content in H-FABP protein was loaded with an approximately equal coefficient in PC 1 as the oxidative catabolic enzyme activities (HAD, CS). The second PC (PC 2, Fig. 3a) illustrated the positive correlation which existed between the intra-muscular activity levels of the three lipogenic enzymes (ACC, ME and G6PDH), and the negative association between these variables and glucose plasma availability. Substantial arrangements for the location of the individuals according to age groups were seen in PC 1 and PC 2 (Fig. 3b). The $10 \mathrm{wk}$ samples were confined to down-right, suggesting that the energy catabolic pathways and H-FABP content were higher and lipogenesis tended to be lower in $10 \mathrm{wk}$ than in 20 wk cardiac samples. The third PC mainly underlined a negative association between $\mathrm{PC}_{\mathrm{TG}}$ and cardiac LPL activity (-0.41; data not shown).

\subsection{Metabolic predictors of intra-muscular fat content}

In the LL muscle, only PC 1 explained a significant variation $(P \leq 0.05)$ in muscle lipid content (Tab. VI). Thus, a high lipogenic capacity and low potential for circulating TG hydrolysis, FA trafficking and nutrient oxidation, together with low plasma concentrations in glucose and TG, correlated positively $\left(r^{2}=0.68, P<0.01\right)$ 

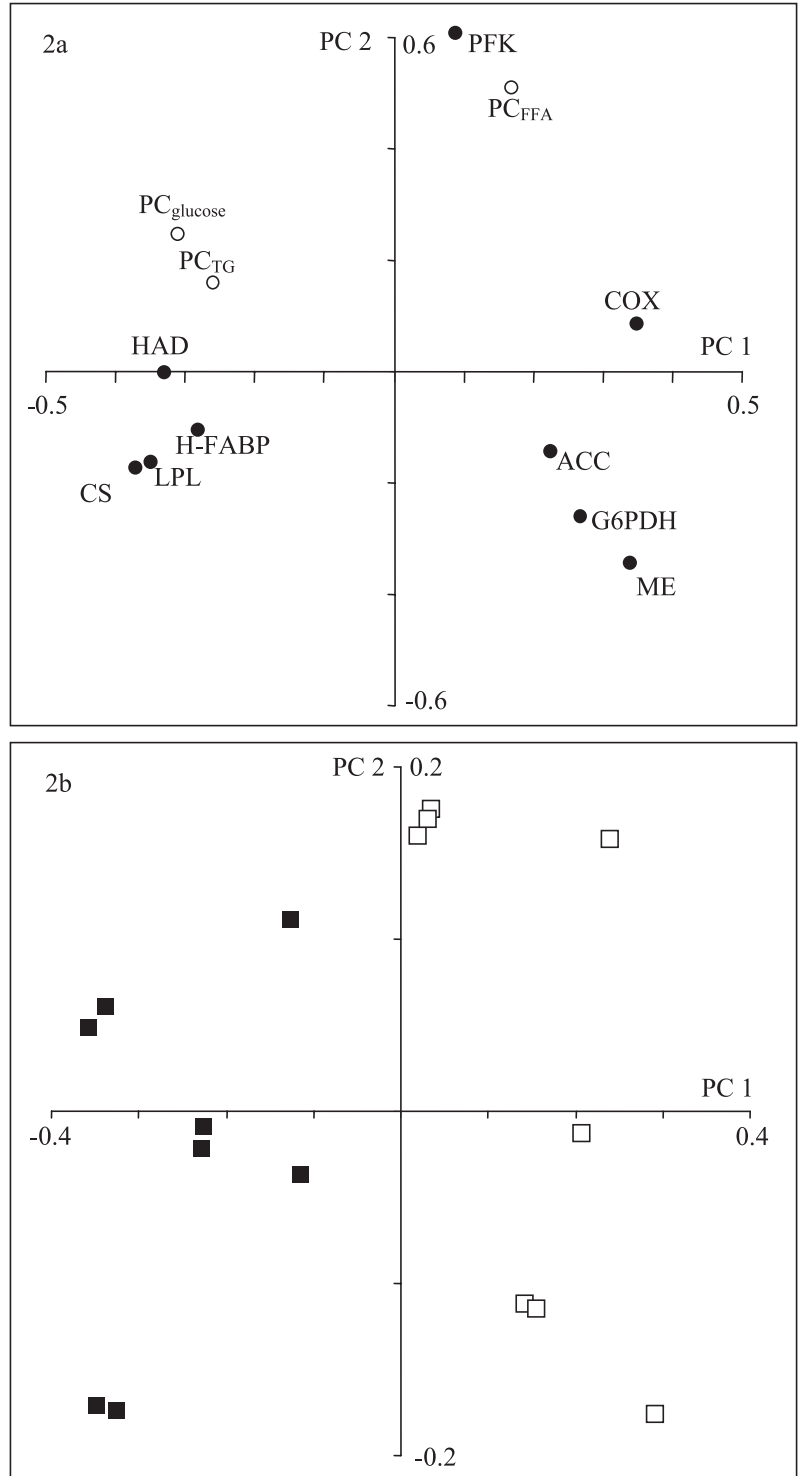

Figure 2. Principal component analyses (PCA) showing relationships between lipogenic enzymes, and oxidative indicators, circulating triglyceride hydrolysis by lipoprotein lipase, and fatty acid transport in the Longissimus lumborum muscle (Principal component 1, PC 1, Fig. 2a). The PCA were performed using the following variables measured in the Longissimus lumborum muscle (•): (i) activities of acetyl-CoA carboxylase (ACC), glucose-6-phosphate dehydrogenase (G6PDH), malic enzyme (ME); (ii) lipoprotein lipase activity (LPL) and content in the heart and skeletal muscle isoform of fatty acid binding protein (HFABP); (iii) activities of citrate synthase (CS), cytochrome- $c$ oxidase (COX), $\beta$-hydroxyacyl-CoA dehydrogenase (HAD), and phosphofructokinase (PFK), and individual scores for plasma profiles in metabolites $\left(\mathrm{O}, \mathrm{PC}_{\mathrm{FFA}}, \mathrm{PC}_{\mathrm{glucose}}\right.$ and $\mathrm{PC}_{\mathrm{TG}}$, see Fig. 1). The position of the points shows the contribution of each original trait to each PC. Variables close to each other are positively associated, whereas variables that lie opposite on the same PC are negatively correlated. The PCA also demonstrated the influence of age (匹: $10 \mathrm{wk}$; $\square$ : $20 \mathrm{wk}$ ) along PC 1 (Fig. 2b). 

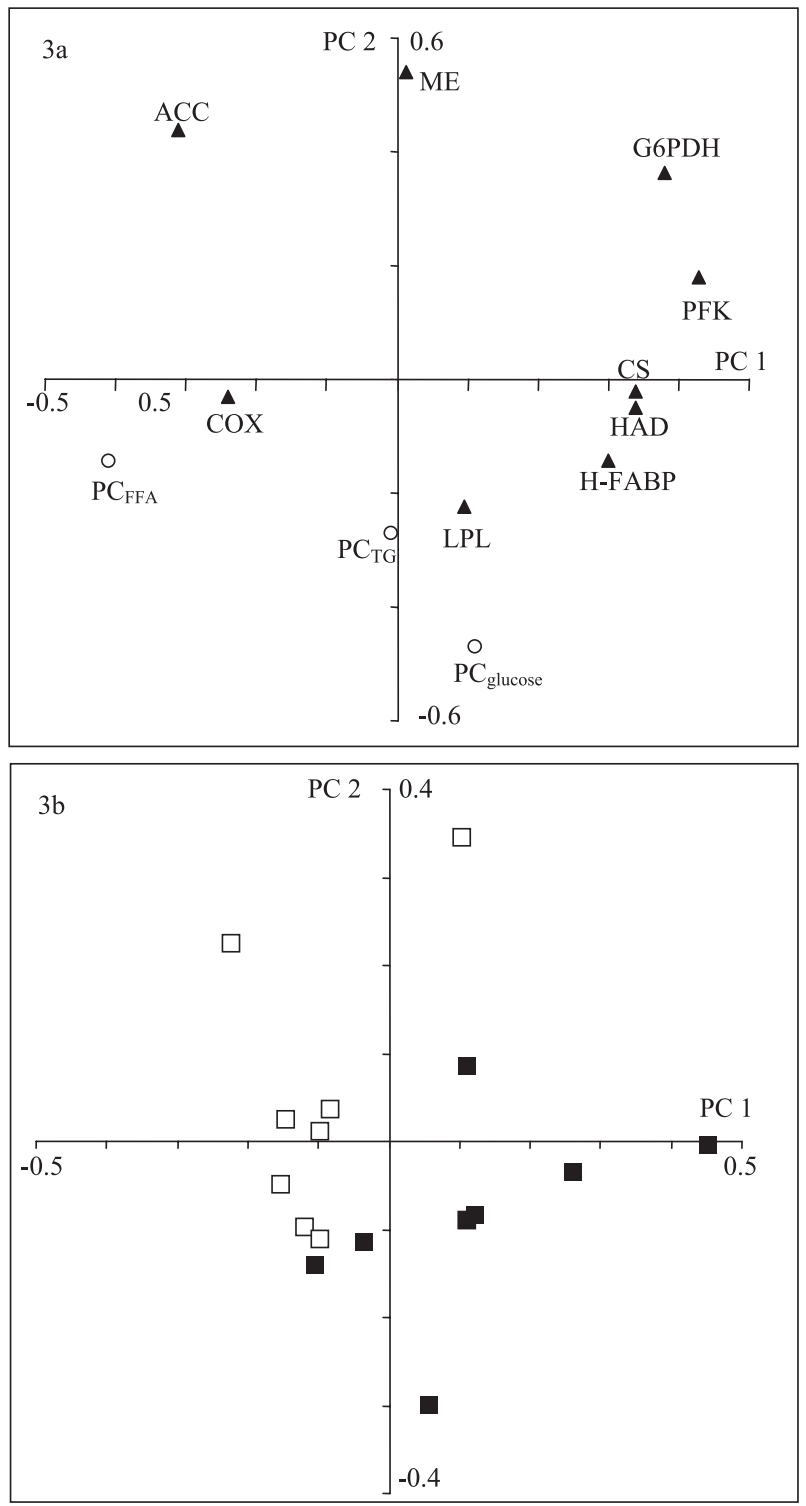

Figure 3. Principal component analyses (PCA) showing relationships between (i) catabolic energy pathways and free fatty acid concentration in plasma (PC 1), and ii) lipogenesis and plasma glucose concentration (PC 2, Fig. 3a). The PCA were performed using the following variables measured in the heart (A): (i) activities of acetyl-CoA carboxylase (ACC), glucose-6-phosphate dehydrogenase (G6PDH), malic enzyme (ME); (ii) lipoprotein lipase activity (LPL) and content in the heart and skeletal muscle isoform of fatty acid binding protein (H-FABP); (iii) activities of citrate synthase (CS), cytochrome-c oxidase (COX), $\beta$-hydroxyacyl-CoA dehydrogenase (HAD), and phosphofructokinase (PFK), and individual scores for plasma metabolite concentrations corrected by extra-muscular metabolisms ( $\mathrm{O}, \mathrm{PC}_{\mathrm{FFA}}, \mathrm{PC}_{\mathrm{glucose}}$ and $\mathrm{PC}_{\mathrm{TG}}$, see Fig. 1). The position of the points shows the contribution of each original trait to each PC. Variables close to each other are positively associated, whereas variables that lie opposite on the same PC are negatively correlated. The PCA also demonstrated the influence of age ( $\square: 10$ wk; $\square: 20$ wk) along PC 1 and PC 2 (Fig. 3b). 
Table VI. Stepwise regression analyses for muscle lipid content from principal components (PC).

\begin{tabular}{lccccc}
\hline Intercept & \multicolumn{2}{c}{ Slope } & & \multicolumn{2}{c}{ Statistics } \\
\cline { 5 - 6 } Mean & Value & Variable $^{1}$ & & $P>\mathrm{F}$ & $\%$ of variance explained \\
\cline { 5 - 6 } $\begin{array}{l}\text { Longissimus lumborum } \\
1.6 \pm 0.1\end{array}$ & & & & 68 \\
Heart & $0.21 \pm 0.05$ & PC 1 & & $<0.01$ & \\
$3.9 \pm 0.2$ & $0.31 \pm 0.1$ & PC 2 & & $<0.01$ & 48 \\
& $-0.15 \pm 0.1$ & PC 1 & & 0.07 & 15
\end{tabular}

${ }^{1} \mathrm{PC}$ were defined as linear combinations of input original variables, with loading coefficients shown in Figure 2a for LL muscle, and in Figure $3 \mathrm{a}$ for the heart $(n=16)$.

to muscle fat accretion. In the heart, two metabolic trends explained $63 \%$ of the total variation in cardiac fat content (Tab. VI): (i) PC 2 was positively correlated to fat content $\left(r^{2}=0.48, P=0.009\right.$, Tab. VI), showing that enhanced lipogenesis (ACC, ME, G6PDH) and low plasma concentration in glucose would favor cardiac lipid deposition; (ii) PC 1 tended to be negatively associated with fat content $\left(r^{2}=0.15, P=0.07\right)$, suggesting that depressed FA trafficking and nutrient catabolism, together with a high plasma FFA level, tend to favor cardiac fat accretion.

\section{DISCUSSION}

As expected [8], glycolytic and oxidative muscles from rabbits at puberty displayed a higher fat content than those harvested in growing animals. Marked increase in muscle lipogenic enzyme activities between the age of $10 \mathrm{wk}$ and $20 \mathrm{wk}$ has been previously observed by us in the LL rabbit [13], but a novel observation in the present study is that a similar rise occurred for cardiac lipogenesis. In our study, CS and HAD activities, which represent oxidative nutrient catabolism, decreased between 10 and $20 \mathrm{wk}$ in the glycolytic LL muscle, a trend similar to that observed for isocitrate dehydrogenase (i.e., an enzyme of the Krebs cycle) in rabbits between the age of 4 and 16 wk [28], and in cattle until puberty [29]. Surprisingly in both muscles and in the liver, COX activity (i.e., an enzyme of the respiratory chain) did not follow the same pattern than the other two oxidative enzyme activities. These results are in line with other data in bovine muscles (Hocquette, personal data). The main contribution of this work was to mathematically determine how age-related changes in these metabolic pathways related to lipogenesis or nutrient catabolism, and in some indicators of tissue potential for circulating TG hydrolysis and nutrient transport, readily accounted for muscle fat accretion. This was achieved by finding combinations between plasma concentrations and several tissue traits, to produce a few numbers of trends representative of metabolic orientation [30]. Interestingly, the first three computed trends adequately described how profiles in plasma metabolites and overall FA metabolism in liver and WAT were associated, and thus argued for the validity of our mathematical approach. First, the relationship between the plasma levels in FFA and variables related to perirenal fat metabolism agreed with the conventional wisdom depicting adipose tissue as the main source of plasma FFA in mammals [31]. Indeed, our results suggest that the less active is fat deposition into WAT, the more active is lipolysis and FFA liberation into the blood. Second, high plasma concentration in TG was correlated to low lipid stores 
in the hepatic cytosol, suggesting that the liver is the main source of circulating TG in animals fed a low fat diet [31]. Third, plasma concentration in glucose was found to be largely assigned to hepatic metabolism, as previously reported in mammals [31]. Because the concentration of metabolites in the venous sampling is the net result of uptake and production by tissues, our results led to the hypothesis that the liver may use greater amounts of glucose to ensure increased lipogenic needs with advancing age, thereby having an impact on plasma glucose disposal for other sites.

Changes in the availability of extra-muscular substrates may modify intra-muscular metabolism pathways, through direct or indirect effects on enzyme activities and gene expression (for a review, see [6]). In the present experiment, plasma glucose disposal and ME and G6PDH activities in both muscles were inversely related, probably because these two enzymes are tightly implicated in the catabolism of glucose. On the contrary, the reasons why the plasma TG level and muscle LPL activity were found positively correlated in the LL muscle and negatively associated in the heart, respectively, remain to be specifically investigated. Tissue-reciprocal regulation of extra-cellular TG hydrolysis occurs in rats, when LPL activity is depressed in response to feeding in the heart but remains unchanged in both oxidative and glycolytic skeletal muscles [32]. In addition, other reports suggest that dietary fat absorption does not influence LPL activity in the heart and in most skeletal muscles in calves unlike in Masseter muscle and in adipose tissues [33]. Finally, in the current study, TG concentration in the venous sampling was the result of hepatic production, absorption, and extra-hepatic tissue clearance via LPL. Therefore, the relationships between circulating TG concentration and muscle LPL activity probably depend on the intrinsic ability of the liver to secrete TG [34], the physiological status of the animals (post-absorptive or feeding conditions), and the local muscle contracting activity $[33,35]$.

Recent investigations using rat hindlimb perfusion preparation [36] suggest that differences in the rate of TG synthesis between various muscles are not only the consequence of variation in blood flow capacities, but are inherent to factors intrinsic to muscle. Our results support this view because muscle traits were associated with approximately equal coefficients as those for plasma indicators in the prediction of muscle fat content. In various species, previous attempts to predict muscle lipid content with only one particular metabolic pathway have often been vain. Indeed, Alasnier and colleagues in rabbits [12] failed to show any strict association between the relative proportion of oxidative fibers in various muscles and their respective fat content. Genetic variants of FABP have been associated with muscle lipid content in pigs [37], but their involvement at the protein level remains unclear [38]. Finally, in line with our results, LPL activity has been negatively associated to marbling in cattle [39]. However, a cause-effect relationship remains uncertain because samples originated from various breeds and different muscles. In the current study, muscle fat accretion was proven to result from a reciprocal balance between muscle capacities of FA synthesis on the one hand, and of FA intracellular trafficking and oxidative catabolism on the other hand. A decreased oxidative enzyme capacity of the skeletal muscle has been postulated to promote lipid deposition in the myocytes and has been identified as a metabolic risk factor of adipose weight gain and obesity (for a review, see [40]), but the rates of de novo lipogenesis within skeletal muscles are thought to be low. Such discrepancies in the relative contributions of lipogenesis and oxidation to muscle fat content in rabbits and humans are probably related to dietary conditions (high-carbohydrate versus high-fat diets, respectively). Also, over-accumulation of TG in the heart of obese rats has been associated with increased cardiac capacity for 
FA esterification and likely lipogenesis, coupled with under-expression of some enzymes of FA oxidation [4]. However, our results suggest that a reduced oxidation contributed much less to an elevated fat content than increased lipogenesis in the heart of normal growing rabbits. Another potential component for the regulation of fat content might be the patterns of expression of various FA binding proteins [11]. Interestingly, the positive close-association between H-FABP content and activity levels of oxidative markers (CS, HAD) in the two muscles currently investigated, suggested a preferential involvement of $\mathrm{H}$ FABP in delivering intracellular FA to sites of oxidation. This was in agreement with other studies in bovine muscles [41] or in H-FABP knockout mice [11].

Finally, it is not clear whether LPL activity might contribute directly or not to the control of muscle fat content in the rabbit. Transgenic mice with muscle LPL only and those with an increased ratio of muscle to adipose tissue LPL have either higher [42] or similar myocyte lipids [43] compared to normal mice. In the current study dealing with fat deposits in both myofibers and interspersed adipocytes, we suggest a negative contribution of LPL to lipid content in the LL. The only elements of interpretation we have arise from the principal component analysis, showing that LPL activity was positively correlated to oxidative enzyme activities (HAD, CS) in the LL muscle. In agreement, transgenic mice that overexpressed LPL specifically in the skeletal muscle, show a dose-dependent induction of oxidative enzymes [44]. Taken together, it is tempting to speculate that decreased FA oxidation from 10 to $20 \mathrm{wk}$ of age resulted in high levels of intracellular FA-derived molecules, thus causing a decrease in LPL activity in a "product control" mechanism [45]. The exact role of LPL in muscle fat deposition remains to be investigated in further experiments, including other dietary (high fat diet), physiological (fasted) and physical (exercised animals) conditions.

\section{CONCLUSION}

Intra-muscular fat content has a tremendous impact for both meat quality in farm animals and human physiology. It is thus of paramount importance in Animal Science and Human Nutrition. However, the overall process involved in muscle fat accretion remains largely unknown. We provide new evidence that the balance between muscle capacities of fatty acid synthesis on the one hand, and of fatty acid intracellular trafficking and oxidation on the other hand, are responsible for fat accretion in the Longissimus lumborum muscle of growing rabbits, and to a lower extent, in the heart. Good strategies for the control of muscle fat content must take into account the balance between fatty acid fluxes, rather than focus on one specific metabolic pathway.

\section{REFERENCES}

[1] Jeukendrup AE, Saris WHM, Wagenmakers AJM. Fat metabolism during exercise: a review. Int J Sports Med 1998, 19: 231-244.

[2] Goodpaster BH, Theriault R, Watkins SC, Kelley DE. Intramuscular lipid content is increased in obesity and decreased by weight loss. Metabolism 2000, 49: 467-472.

[3] Kelley DE, Goodpaster BH. Skeletal muscle triglyceride. An aspect of regional adiposity and insulin resistance. Diabetes Care 2001, 24: 933-941.

[4] Zhou YT, Grayburn P, Karim A, Shimabukuro M, Higa M, Baetens D, Orci L, Unger RH. Lipotoxic heart disease in obese rats: implications for human obesity. Proc Natl Acad Sci USA 2000, 97: 1784-1789.

[5] Demeyer D, Doreau M. Targets and procedures for altering ruminant meat and milk lipids. Proc Nutr Soc 1999, 58: 593-607.

[6] Hocquette JF, Ortigues-Marty I, Pethick D, Herpin P, Fernandez X. Nutritional and hormonal regulation of energy metabolism in skeletal muscles of meat-producing animals. Livest Prod Sci 1998, 56: 115-143.

[7] Taylor JM. Transgenic rabbit models for the study of atherosclerosis. Ann NY Acad Sci 1997, 811: 146-151. 
[8] Gondret F, Mourot J, Bonneau M. Comparison of intramuscular adipose tissue cellularity in muscles differing in their lipid content and fiber type composition during rabbit growth. Livest Prod Sci 1998, 54: 1-10.

[9] Lebas F, Retailleau B, Hurtaud J. Évolution de quelques caractéristiques bouchères et de la composition corporelle de 2 lignées de lapins entre 6 et 20 semaines d'âge. In: ITAVI (Ed), Proc. 9th J Rech Cunicole, 2001, p 55-58.

[10] Chen HC, Farese RV Jr. Fatty acids, triglycerides, and glucose metabolism: recent insights from knockout mice. Curr Opin Clin Nutr Metab Care 2002, 5: 359-563.

[11] Zimmerman AW, Veerkamp JH. New insights into the structure and function of fatty acidbinding proteins. Cell Mol Life Sci 2002, 59: 1096-1116.

[12] Alasnier C, Rémignon H, Gandemer G. Lipid characteristics associated with oxidative and glycolytic fibres in rabbit muscles. Meat Sci 1996, 43: 213-224.

[13] Gondret F, Mourot J, Bonneau M. Developmental changes in lipogenic enzymes in muscle compared to liver and extramuscular adipose tissues in the rabbit (Oryctolagus cuniculus). Comp Biochem Physiol B 1997, 117: 259-265.

[14] Leung TT, Bauman DE. In vivo studies of the site of fatty acid synthesis in the rabbit. Int $\mathrm{J}$ Biochem 1975, 6: 801-805.

[15] Reiser PJ, Kline WO. Electrophoretic separation and quantification of cardiac myosin heavy chain isoforms in eight mammalian species. Am J Physiol 1998, 43: H1048H1053.

[16] Folch J, Lee M, Sloane-Stanley GH. A simple method for the isolation and purification of total lipids from animal tissues. J Biol Chem 1957, 226: 497-509.

[17] Hocquette JF, Graulet B, Olivecrona T. Lipoprotein lipase activity and mRNA levels in bovine tissues. Comp Biochem Physiol 1998, 121B: 201-211.

[18] Zechner R. The tissue-specific expression of lipoprotein lipase: implications for energy and lipoprotein metabolism. Curr Opin Lipid 1997, 8: 7-88.

[19] Piot C, Hocquette JF, Herpin P, Veerkamp JH, Bauchart D. Dietary coconut oil affects more lipoprotein lipase activity than the mitochondria oxidative capacities in muscles of pre-ruminant calves. J Nutr Biochem 2000, 11: 231-238.
[20] Bazin R, Ferré P. Assays of lipogenic enzymes. Methods Mol Biol. 2001, 155: 121-127.

[21] Chang HC, Seidman I, Teebor G, Lane DM. Liver acetyl-CoA carboxylase and fatty acid synthetase: relative activities in the normal state and hereditary obesity. Biochem Biophys Res Commun 1967, 28: 682-686.

[22] Bass A, Brdiczka D, Eyer P, Hofer S, Pette D. Metabolic differentiation of distinct muscle types at the level of enzymatic organization. Eur J Biochem 1969, 10: 198-206.

[23] Shepherd D, Garland PB. Citrate synthase from rat liver. Methods Enzymol 1969, 13: $11-16$.

[24] Van Hinsberg VWM, Veerkamp JH, Bookelman H. Palmitate oxidation by rat skeletal muscle mitochondria. Comparison of polaographic and radiochemical experiments. Arch Biochem Biophys 1978, 190: 762-771.

[25] Beutler E. Phosphofructokinase. In: Beutler E (Ed), Red cell metabolism. A manual of biochemical methods, Grune and Straton Inc., NY, 1971, p 42-44.

[26] Naes T, Baardseth P, Helgesen H, Isaksson T. Multivariate techniques in the analysis of meat quality. Meat Sci (Suppl) 1996, 43: 135-149.

[27] Lewis GP, Matthews J. The mobilization of free fatty acids from rabbit adipose tissue in situ. Br J Pharmacol 1968, 34: 564-578.

[28] Briand M, Boissonnet G, Laplace-Marieze V, Briand Y. Metabolic and contractile differentiation of rabbit muscles during growth. Int $\mathbf{J}$ Biochem 1993, 25: 1881-1887.

[29] Jurie C, Robelin J, Picard B, Geay Y. Postnatal changes in the biological characteristics of Semitendinosus muscle in male Limousin cattle. Meat Sci 1995, 41: 125-135.

[30] Ortigues-Marty I, Hocquette JF, Bertrand G, Martineau C, Vermorel M, Toullec R. The incorporation of solubilized wheat proteins in milk replacers for veal calves: effects on growth performance and muscle oxidative capacity. Reprod Nutr Dev 2003, 43: 57-76.

[31] Murray RK, Granner DK, Mays PA, Rodwell VW. Harper's Biochemistry. De Boeck Univ Press, Laval, 1993.

[32] Ong JM, Simsolo RB, Saghizadeh M, Pauer A, Kern PA. Expression of lipoprotein lipase in rat muscle: regulation by feeding and hypothyroidism. J. Lipid Res 1994, 35: $1542-1551$. 
[33] Hocquette JF, Graulet B, Vermorel M, Bauchart D. Weaning affects lipoprotein lipase activity and gene expression only in adipose tissues and in masseter but not in other muscles of the calf. Br J Nutr 2001, 86: 433-441.

[34] Bonnet M, Leroux C, Faulconnier Y, Hocquette JF, Bocquier F, Martin P, Chilliard Y. Lipoprotein lipase activity and mRNA are up-regulated by refeeding in adipose tissue and cardiac muscle of sheep. J Nutr 2000, 130: 749-756.

[35] Hamilton MT, Etienne J, McClure W, Pavey BS, Holloway AK. Role of local contractile activity and muscle fiber type on LPL regulation during exercise. Am J Physiol 1998, 275 . E1016-E1022

[36] Budohoski L, Gorski J, Nazar K, KaciubaUscilko H, Terjung RL. Triacylglycerol synthesis in the different skeletal muscle fiber sections of the rat. Am J Physiol 1996, 271: E574-E581.

[37] Gerbens F, van Erp AJ, Harders FL, Verburg FJ, Meuwissen TH, Veerkamp JH, Te Pas MF. Effect of genetic variants of the heart fatty acid binding protein gene on intramuscular fat and performance traits in pigs. J Anim Sci 1999, 77: 846-852.

[38] Gerbens F, Verburg FJ, Van Moerkerk HTB, Engel B, Buist W, Veerkamp JH, Te Pas MFW. Associations of heart and adipocyte FABP gene expression with intramuscular fat content in pigs. J Anim Sci 2001, 79: 347 354.

[39] Jurie C, Sabboh H, Boulesteix P, Bauchart D, Pethick DW, Hocquette JF. Contribution de différentes voies métaboliques du muscle et du tissu adipeux intramusculaire au persillage de la viande bovine. In: Proc. 9th Renc Rech Ruminants, 2002, p 263.

[40] Astrup A, Raben A, Buemann B, Toubro S. Fat metabolism in the predisposition to obesity. Ann NY Acad Sci 1997, 827: 417-430.

[41] Brandstetter AM, Sauerwein H, Veerkamp JH, Geay Y, Hocquette JF. Effects of muscle type, castration, age and growth rate on $\mathrm{H}$ FABP expression in bovine skeletal muscle. Livest Prod Sci 2002, 75: 199-208.

[42] Weinstock PH, Levak-Frank S, Hudgins LC, Radner H, Friedman JM, Zechner R, Breslow JL. Lipoprotein lipase controls fatty acid entry into adipose tissue but fat mass is preserved by endogenous synthesis in mice deficient in adipose tissue lipoprotein lipase. Proc Natl Acad Sci USA 1997, 94: 10261-10266.

[43] Levak-Frank S, Radner H, Walsh A, Stollberger R, Knipping G, Hoefler G, Sattler W, Weinstock P, Breslow JL, Zechner R. Muscle-specific overexpression of lipoprotein lipase causes a severe myopathy characterized by proliferation of mitochondria and peroxisomes in transgenic mice. J Clin Invest 1995, 96: 976-986.

[44] Hoefler G, Noehammer C, Levak-Frank S, El-Shabrawi Y, Schauer S, Zechner R, Radner $\mathrm{H}$. Muscle-specific overexpression of human lipoprotein lipase in mice causes increased intracellular free fatty acids and induction of peroxisomal enzymes. Biochimie 1997, 79: 163-168.

[45] Peterson J, Bihain BE, Bengtsson-Olivecrona G, Deckelbaum RJ, CarpentierYA, Olivecrona T. Fatty acid control of lipoprotein lipase: a link between energy metabolism and lipid transport. Proc Natl Acad Sci USA 1990, 87: 909-913. 